\title{
Antibiotics, gut microbiota, and Alzheimer's disease
}

\author{
Francesco Angelucci ${ }^{*} \mathbb{D}$, Katerina Cechova, Jana Amlerova and Jakub Hort
}

\begin{abstract}
Alzheimer's disease (AD) is a neurodegenerative disease whose various pathophysiological aspects are still being investigated. Recently, it has been hypothesized that AD may be associated with a dysbiosis of microbes in the intestine. In fact, the intestinal flora is able to influence the activity of the brain and cause its dysfunctions.

Given the growing interest in this topic, the purpose of this review is to analyze the role of antibiotics in relation to the gut microbiota and AD. In the first part of the review, we briefly review the role of gut microbiota in the brain and the various theories supporting the hypothesis that dysbiosis can be associated with AD pathophysiology. In the second part, we analyze the possible role of antibiotics in these events. Antibiotics are normally used to remove or prevent bacterial colonization in the human body, without targeting specific types of bacteria. As a result, broadspectrum antibiotics can greatly affect the composition of the gut microbiota, reduce its biodiversity, and delay colonization for a long period after administration. Thus, the action of antibiotics in AD could be wide and even opposite, depending on the type of antibiotic and on the specific role of the microbiome in AD pathogenesis. Alteration of the gut microbiota can induce changes in brain activity, which raise the possibility of therapeutic manipulation of the microbiome in $\mathrm{AD}$ and other neurological disorders. This field of research is currently undergoing great development, but therapeutic applications are still far away. Whether a therapeutic manipulation of gut microbiota in $A D$ could be achieved using antibiotics is still not known. The future of antibiotics in AD depends on the research progresses in the role of gut bacteria. We must first understand how and when gut bacteria act to promote AD. Once the role of gut microbiota in AD is well established, one can think to induce modifications of the gut microbiota with the use of pre-, pro-, or antibiotics to produce therapeutic effects.
\end{abstract}

Keywords: Alzheimer's disease, Gut microbiota, Antibiotics, Neuroinflammation

\section{Introduction}

Alzheimer's disease (AD) is a neurodegenerative disease whose various pathophysiological aspects are still under investigation [1]. It is a disorder characterized by a progressive decline in cognitive functions and loss of specific types of neurons and synapses. The most recognized pathological events in AD are amyloid plaques and neurofibrillary tangles [2]. Amyloid plaques are extracellular accumulations of abnormally folded amyloid beta $(A \beta)$ proteins with 40 or 42 amino acids (A $\beta 40$ and $A \beta 42)$, two by-products of amyloid precursor protein (APP) metabolism [3]. Neurofibrillary tangles are primarily composed of paired helical filaments consisting of hyperphosphorylated tau, a protein stabilizing microtubules [3]. The etiology of

\footnotetext{
* Correspondence: francesco.angelucci@lfmotol.cuni.cz

Memory Clinic, Department of Neurology, 2nd Faculty of Medicine, Charles University and Motol University Hospital, Prague, Czech Republic
}

$\mathrm{AD}$ is multifactorial. There exist sporadic forms and familial forms associated with mutations in three genes: APP, presenilin 1 (PSEN1), and presenilin 2 (PSEN2). Familial forms are more rare $(<0.5 \%)$ as compared to sporadic forms [1]. Nowadays, it is believed that genetic and environmental factors interact to induce $\mathrm{AD}$ onset.

Recently, it has been hypothesized that AD may be associated with a dysbiosis of microbes in the intestine [4]. This hypothesis is linked to the fact that the intestinal flora is able to influence the activity of the brain and cause its dysfunctions $[2,5]$. Growing evidence in this field led to the definition of the term microbiota-gut-brain axis (MGBA) [6]. The association between gut microbiota and $\mathrm{AD}$ is also related to the central role of inflammation in the development and course of AD [7]. Given the growing interest in this topic, the purpose of this review is to

(c) The Author(s). 2019 Open Access This article is distributed under the terms of the Creative Commons Attribution 4.0 International License (http://creativecommons.org/licenses/by/4.0/), which permits unrestricted use, distribution, and 
analyze the role of antibiotics in relation to the gut microbiota and AD.

\section{Gut microbiota}

Thousands of species of microbes that influence the physiology and development of the individual, as well as the maintenance of the host's health, populate our intestine (or gut). Among gut microbes, there can be distinguished bacteria, viruses, and fungi. In a healthy organism, these microorganisms regulate the digestive $\mathrm{pH}$ and, in turn, create a protective barrier against the infectious agents.

These "good" microbes are called probiotic: a living microorganism that produces beneficial effects on the health of the host person [8]. Probiotic bacteria contribute to make the necessary substances available to our body, to avoid inflammation and related diseases. The whole chain of reactions favorable to our health occurs only when the intestinal bacterial flora is in equilibrium. To favor this equilibrium, it is necessary to consume enough quantity of these probiotics trough the diet. The most common ones are Bifidobacteria and Lactobacillus strains. They are found in some type of food such as yogurt, fermented cheese, and vegetables, or they can be consumed as dietary supplements. A good variety of microbiota strain can be achieved by a large variety diet, including the habit to consume other types of food during traveling. However, poor eating habits, antibiotic consumption, and stress can compromise their activity and/or alter their composition, creating an imbalance that puts health at risk. The diseases associated to an alteration of the gut microbiota are varied and include colorectal cancer, metabolic syndrome, obesity, allergies, inflammatory bowel disease, type 2 diabetes, and heart failure [9].

\section{Gut microbiota and brain}

The relationship between the gut microbiota and the central nervous system is because the intestine and the brain can interact with each other through the nervous system or chemical substances crossing the blood-brain barrier. In particular, the vagus nerve connects intestinal neurons with those of the central nervous system [10]. The gut microbiota produces substances (i.e., monoamines and amino acids) that, through the lymphatic and vascular system, reach the central neurons and can influence their activity, with possible repercussions on behavior [11]. In addition, gut bacteria are receptive to the messages sent by the brain in the form of neurotransmitters $[7,12]$.

Several pathways of communication between the gut and brain have been studied [13]. Vagus nerve serves as a link between the gut and the spinal cord (autonomic nervous system) [14]. The vagus nerve ends to brain stem nuclei that receive and give afferent and efferent fibers [14]. In this way, brain stem nuclei may control many gut functions and send signals to other brain regions, such as the thalamus and cortical areas [15]. In addition, the enteric nervous system can exchange signals with the central nervous system through the gut bacteria [16]. Exchanges between gut and brain can also occur through the blood circulation [17]. Intestinal mucosa and blood-brain barriers allow the passage of immune and endocrine molecules, such as cytokines and hormones, able to influence both gut and brain functions [18]. Interestingly, it has been shown in germ-free mice that gut bacteria influence the maturation of the immune, endocrine, and nervous system [15]. The MGBA can be seen as a multifunctional network, where central, peripheral, immune, and endocrine systems participate to the bidirectional communication [19].

The way in which the gut microbiota regulates MGBA can be of various kinds. First, these microorganisms are able to synthesize and release neurotransmitters and neuromodulators, such as short-chain fatty acids (SCFAs), biogenic amines (e.g., serotonin, histamine, and dopamine), and other amino acid-derived metabolites such as serotonin or GABA and tryptophan [13]. All these molecules act as neurotransmitters or as neurotransmitter precursors in the brain and regulate neuronal activity. Nonetheless, there is still the need for more robust experimental evidences to prove that gut microbiota alterations are responsible for changes in behavior. Many studies indeed evidenced this correlation but did not prove a direct cause-effect [20].

Another possibility is that the gut microbiota produces toxic substances to the brain. The gut microbiota can release neurotoxic substances, such as D-lactic acid and ammonia [21]. Moreover, during a process of inflammation, the gut microbiota releases other proteins potentially harmful to the brain, such as proinflammatory cytokines and other innate immune activators in the host [22]. Thus, the microbiota can affect the MGBA via immunological, neuroendocrine, and direct neural mechanisms [17]. The result of this alteration in the brain can lead to memory impairment, anxiety, and other cognitive dysfunctions $[20,21,23,24]$. According to the recent studies, changes in gut microbiota are associated to various neurological diseases [25], which include not only anxiety and depression [26], but also neurodegenerative diseases [6] or drug-resistant epilepsy [27]. Among neurodegenerative diseases, there are evidences for a possible involvement of gut dysbiosis in AD [4], Parkinson's [28] and Huntington's [29] diseases, and multiple sclerosis [30].

\section{Alzheimer's disease: the role of inflammation}

The connection between the gut microbiota and $\mathrm{AD}$ was hypothesized because of the role of inflammation in this pathology [7]. The brain is able to initiate an immune 
response following different insults, such as pathogens or any other harmful event. Under normal conditions, this immune response is initiated by microglia and terminates with the elimination of pathogens, dead cells or other cellular debris, and tissue restoration. However, under certain pathological conditions in which the insult persists or the immune response is altered or compromised, a process of chronic inflammation can be harmful to neurons. The term "neuroinflammation" refers to the fact that the neurons release substances that sustain the inflammatory process and the immune response. The immune responses can therefore be beneficial or detrimental to the brain, depending on the strengths of their activation.

A prolonged neuroinflammatory process has been shown to be the cause or consequence of some neurodegenerative diseases [31] including $\mathrm{AD}$ [32]. In particular, elevated serum levels of proinflammatory cytokines such as interleukin (IL)-1 and IL-6, TNF-alpha, and TGFbeta, which have a central role in neuroinflammation, have been observed in AD patients [33, 34]. The constant release of cytokines by microglia and astrocytes seems to be due to the continuous deposition of the $A \beta$ peptide in the extracellular space [32, 34]. According to the amyloid cascade hypothesis, these deposits lead to the synaptic dysfunction and underlie the clinical symptoms of dementia observed in AD. Nonetheless, this hypothesis has been challenged by repeated failures of clinical trial with $\mathrm{A} \beta$-targeting drugs [35]. It has become evident that $\mathrm{A} \beta$ dyshomeostasis is upstream of alterations in other proteins and diverse cell types that contribute to the $\mathrm{AD}$ cognitive phenotype. The role of microglia activation, in response to $A \beta$ deposition, has emerged as an important factor in AD pathogenesis [36, 37]. Some genes encoding for proteins of the innate immune response have been identified as a key element of AD pathophysiology. Among them, complement receptor 1 [38], CD33 [39], and TREM2 [40] appear to be involved either directly or indirectly in the response of microglia to $A \beta$ deposition. As shown in transgenic animal models, alterations of these genes lead to a dysfunctional response of microglia, which fail to cluster around $A \beta$ plaques [40-42].

In addition, recent data indicate that $A \beta$ itself, although it was thought to be a proinflammatory peptide $[26,43]$, appears to have an innate antimicrobial activity [44]. These data suggest that neuroinflammatory processes may be the cause, and not the consequence, of the neurodegenerative processes of AD. Nonetheless, it is yet not clear whether inflammation is the primary event in $\mathrm{AD}$ as many studies have shown that $\mathrm{A} \beta$ deposition may precede microgliosis $[45,46]$. The latest hypotheses suggest that a vicious cycle between $A \beta$ accumulation and microglia activation is present in the brain of $\mathrm{AD}$ patients [46] and that microglia-induced neuroinflammation may be a target for anti-AD drug development [47].

In this context, the idea has developed that an alteration of the gut microbiota, a condition called dysbiosis, may be one of the factors contributing to the neuroinflammatory processes observed in $\mathrm{AD}$ [48].

\section{Dysbiosis as an inducing factor in $A D$}

Many studies in recent years have highlighted the role of gut microbiota in AD pathophysiology [4, 49]. Some theories based on a role of gut microbiota have been proposed, including a direct action of these microbes (microbial infection in AD) [50], indirect actions (antimicrobial protection hypothesis, hygiene hypothesis) $[29,31,49,51]$, and processes related to the aging of the immune system [52].

\section{Direct microbial infection in AD}

The demonstration that the gut microbiota is able to participate in $\mathrm{AD}$ pathophysiology comes primarily from studies in laboratory animals. In this regard, studies with rodent-free pathogens, the so-called germ-free, are important. In these animals, a significant reduction of the $A \beta$ pathology was observed, which is present again when the mice are exposed to the gut microbiota of the control mice [53].

In humans, many studies have also recently shown that a viral or bacterial infection can be one of the triggering causes of AD. It has been shown that chronic Helicobacter (H.) pylori infection in $\mathrm{AD}$ patients triggers the release of inflammatory mediators and is associated with decreased MMSE score as compared to non-infected patients [54]. Moreover, the serum levels of $A \beta 40$ and $\mathrm{A} \beta 42$ are higher in $\mathrm{AD}$ patients infected by $H$. pylori and other bacteria, such as Borrelia burgdorferi and Chlamydia pneumoniae [55]. In neuroblastoma cells, it was also demonstrated that exposure to $H$. pylori filtrate induces a tau hyperphosphorylation resembling that observed in AD tau pathology [56].

All these bacteria can act synergistically to induce an infection burden in the brain of AD patients [57]. In hippocampal and temporal lobe lysates from $A D$ brains, high levels of bacterial lipopolysaccharide were observed [58]. Analysis of blood in patients with brain amyloidosis and cognitive impairment also revealed increased levels of proinflammatory cytokines, together with higher proinflammatory (Escherichia/Shighella) and reduced anti-inflammatory (Escherichia rectale) gut microbes [59]. A viral infection was also hypothesized in AD [50]. In particular, many studies have shown that herpes simplex virus type 1 (HSV1) represents an important risk factor for the development of the disease, especially for ApoE- $\varepsilon 4$ carriers [60]. Other viruses, such as Cytomegalovirus (CMV) [61] and varicella-zoster virus [62], have also 
been associated with $\mathrm{AD}$, although the role of these viruses as individual AD risk factors is not clear [63, 64].

Brain alterations caused by dysbiosis that can promote AD can occur in many ways. First, as already mentioned, these bacteria are responsible for possible alterations in the levels of certain neurotransmitters. In addition, some studies have shown that gut microbiota can also alter proteins and receptors involved in synaptic plasticity [65], such as NMDA receptors, brain-derived neurotrophic factor (BDNF), and serotonin receptors, in addition to serotonin itself. Inflammation also plays a fundamental role. Dysbiosis can generate a neuroinflammatory state with the production of proinflammatory cytokines and the loss of immune regulatory function [66]. Furthermore, under normal conditions, the gut microbiota is responsible for the production of neuroprotective molecules such as fatty acids and antioxidants $[67,68]$.

\section{Age-related dysbiosis and AD}

The clinical and experimental evidences of a link between gut microbiota and AD have led to the so-called theory of "age-related dysbiosis," which hypothesizes that AD may arise during the process of aging of the immune system. In fact, it has been observed that during the aging, there are changes in the composition of the gut microbiota, the increase of proteobacteria, and a reduction of probiotics, such as bifidobacteria, and neuroprotective molecules, such as SCFAs [38, 69]. Moreover, an association between the loss of microbiome function, specifically genes that encode SCFAs, and increased levels of circulating proinflammatory cytokines has been shown in healthy elderly people [70].

It has been suggested that the processes of age-related dysbiosis and neurological decline are linked through the former mediating chronic low-grade inflammation as a common basis for a broad spectrum of age-related pathologies, or so-called inflamm-aging [71].

\section{Antimicrobial protection in AD}

In line with these findings, the hypothesis of antimicrobial protection in $\mathrm{AD}$ was postulated [51]. According to this theory, the accumulation of $A \beta$ in the brain is an epiphenomenon that represents an immune response to the accumulation of harmful bacteria. This theory is supported by numerous data that indicate that the peptide $A \beta$ represents a natural antimicrobial agent but, during the $\mathrm{AD}$ course, the protracted neuroinflammatory state caused by the gut microbiota leads to a non-interruption of this process, with consequent $A \beta$ accumulation of brain [51].

At the same time, however, it should be noted that the complete absence of gut microbiota is detrimental to the functioning of the brain. If we destroy the bacterial flora using antibiotics in animal models of $\mathrm{AD}$, we can see a reduction in $A \beta$ deposits but also an increase in inflammatory molecules such as cytokines and chemokines and an activation of microglia [72]. Thus, a simple reduction of gut microbiota can be deleterious.

\section{Hygiene hypothesis of AD}

With this in mind, the hygiene hypothesis of $\mathrm{AD}$ has been proposed. The hygiene hypothesis of $\mathrm{AD}$ points to the excessive sanitation in early life as the cause of subsequent disturbances of the components of the immune system $[29,49]$. In this regard, it has been observed that the microglia of germ-free animals seem to be less reactive to inflammatory processes caused by viruses and bacteria, and generally have a reduced, or at least altered, basal surveillance level [73]. The hygiene hypothesis of $\mathrm{AD}$ predicts the negative correlation with microbial diversity and is positively associated with environmental sanitation [74].

Dysfunction of the immune system induced by inadequate stimulation to immunity may result in an increased risk of $\mathrm{AD}$ through $\mathrm{T}$ cell system [75]. Some interesting studies suggest that the functionality of regulatory $\mathrm{T}$ (Treg) cells, fundamental elements of Th1-mediated inflammation, is impaired in $\mathrm{AD}$ patients and that mild cognitive impaired (MCI) patients have not only a high number of Treg cells as compared to controls [76] but also a higher Treg-induced immunosuppression [77]. In addition, inadequate Treg function in these patients augments the risk of conversion from MCI to $\mathrm{AD}$ [78] while individuals with adequate Treg function may stay longer in the MCI phase [79].

These data highlight the importance of immune cell components in the development of AD and further support the hygiene hypothesis. In addition, some studies have shown that subjects carrying genes of AD familiar forms, such as apolipoprotein E (ApoE)-4 allele carriers, present an increased risk of $\mathrm{AD}$ conversion in the presence of viral infections $[49,80]$ or food regimes $[50,81]$ harmful to gut bacteria.

In conclusion, any element that disturbs the intestinal flora and its balance can be a triggering factor for neurological disorders, including AD, especially during the old age where the immune defenses are lacking or are reduced. Among these elements, we can include not only microbial infections but also other factors, such as diet and the use of antibiotics.

\section{Antibiotics, gut microbiota, and Alzheimer's disease}

If the gut microbiota plays an important role in $A D$, substances that are able to modify its composition, such as antibiotic agents, can positively or negatively affect the disease. Antibiotics are normally used to remove or prevent bacterial colonization in the human body, without targeting specific types of bacteria. As a result, broad-spectrum 
antibiotics can greatly affect the composition of the gut microbiota, reduce its biodiversity, and delay colonization for a long period after administration.

A number of studies showed that different antibiotic treatments result in short- and/or long-term changes in the intestinal microbiota in both humans and animals [82]. In addition, both animal and clinical studies have demonstrated that the use of antibiotics and the concomitant dysbiosis is associated with changes in behavior and brain chemistry $[83,84]$.

In humans, it has been demonstrated that antibiotic use, when administered as a cocktail therapy, is associated with neurological disorders that include anxiety and panic attacks to major depression, psychosis, and delirium [85]. Despite this, the normal use of antibiotics in the general population is not typically associated with neuropsychiatric side effects. With regard to $A D$, it has been shown that the use of cocktail of antibiotics (ABX) in APP/PS1 transgenic mice can increase the neuroinflammatory state and cytokine levels and therefore the disease itself [72].

Among the harmful antibiotics, there are those that destroy the balance of gut bacteria, such as streptozotocin and ampicillin [86]. According to the hypotheses on gut microbiota and $\mathrm{AD}$, the use of these antibiotics favors the disease or worsens its course. The administration of ampicillin in rats produced an elevation of serum corticosterone and increased the anxiety-like behavior and impairment of spatial memory [87]. Elevated glucocorticoids are associated with memory dysfunctions and reduction of hippocampal BDNF, two common features of AD pathology. Interestingly, the administration of probiotics (Lactobacillus fermentum strain NS9) reverses the physiological and psychological abnormalities induced by ampicillin in rats [87]. In this regard, germ-free mice are also characterized by similar molecular alterations, such as of anxiety-like behavior [88] and changes in the expression of tight junction proteins, BDNF [89], GRIN2B, the serotonin transporter, the NPY system [84], and HPA axis activity.

It has been also demonstrated that NMDA receptor expression might be dependent on the presence of gut microbiota. The mRNA expression of hippocampal NMDA receptor subtype $2 B$ (NR2B) is significantly decreased in germ-free mice [88]. Disruption of gut microbiota by ampicillin treatment also significantly reduces the level of NMDA receptor in the rat hippocampus [87].

Further support to this notion is the fact that antibiotics such as streptozotocin have been used to induce sporadic $A D$ forms in animal models with effects on learning and memory performances $[59,90]$. The same antibiotic is used to induce diabetes mellitus in animals $[60,91]$ which is a frequent comorbidity of AD characterized by cognitive decline $[61,92]$. Moreover, the administration of probiotic substances as a food supplement has beneficial effects on the synaptic activity and cognitive function in streptozocin-induced diabetes rat models [93].

In line with the hygiene hypothesis of the disease, there is evidence that the administration of antibiotic cocktails in adolescent mice can cause permanent alterations of the gut microbiota and increase in proinflammatory cytokines, with long-lasting effects on cognitive function in the adult $[94,95]$. In humans, some antibiotics, i.e., cefepime, can cross the blood-brain barrier and cause altered mental status, with reduced consciousness, myoclonus, and confusion [65,96], without the mediation of gut microbiota. On the other hand, antibiotics can also have beneficial effects on AD. These effects are due to the fact that an alteration of the gut microbiota, not necessarily caused by antibiotics, can promote the development of bacteria that could be harmful to the brain (microbial hypothesis) [24]. The elimination of pathogenic bacteria such as Helicobacter pylori by triple eradication antibiotic regimen (omeprazole, clarithromycin, and amoxicillin) has led to positive results for cognitive and functional status parameters in AD patients [97].

A series of studies have also shown that some antibiotics, by reducing neuroinflammation due to dysbiosis, can have beneficial effects in AD. These effects include neuroprotection and anti-inflammatory, anti-tau, anti-amyloid, and cholinergic effects. The administration of rifampicin in $A D$ animal models reduces the brain levels of $A \beta$ and inflammatory cytokines [98]. Minocycline has also similar effects on $A \beta$ and reduces microglia activation in rodent $A D$ models [99]. Similarly, rapamycin has been shown to reduce not only $A \beta$ and the microglia activation, but also tau phosphorylation [100]. D-Cycloserin, which is also a NMDA receptor partial agonist, improves cognitive deficits in aged rats [101] and in AD patients [102].

All these antibiotics have been proved to reduce inflammation and improve cognitive deficits in AD animal models, while controversial results have been obtained in some clinical trials.

In 2004, doxycycline and rifampin given in combination showed a significant improvement in the Standardized Alzheimer's Disease Assessment Scale cognitive subscale (SADAScog) at 6 months in patients with probable AD and mild to moderate dementia [103]. In 2013 instead, a multicenter, blinded, randomized, $2 \times 2$ factorial controlled trial in patients with mild to moderate AD showed no significant effect on cognition after 12 months of treatment with doxycycline or rifampin, alone or in combination [104]. Similarly, in 1999, D-cycloserine was found effective in improving cognitive deficits in patients with $\mathrm{AD}$ [102] but these positive effects were not replicated in successive trials [105]. 
The presence or absence of bacterial infections, like $H$. pylori [97], susceptible to antibody action may be responsible for these contrasting data. Nonetheless, these studies provide evidence for a possible role of antibodies in AD through their action on gut bacteria.

In addition, besides contrasting neuroinflammation [99], antibiotics can also have beneficial effects in AD through other mechanisms. This is the case of rapamycin, which, in addition to having so-called antiaging properties [106], is in fact the natural inhibitor of the mammalian enzyme target of rapamycin (mTOR). Upregulation of the mTOR signaling pathway plays an important role in major pathological processes of AD. The administration of MTOR inhibitors, like rapamycin, ameliorate the AD-like pathology and cognitive deficits in a broad range of animal models [100], indicating their potential as therapeutics.

Despite these findings, the option to use antibiotics to treat $\mathrm{AD}$ and other neurodegenerative disorders should be carefully evaluated in humans. The possible benefits can be counteracted by the insurgence of antibiotic resistance. At present, there is lack of scientific evidences for the use of antibiotics as therapeutic agents for AD.

\section{Probiotics, prebiotics, and Alzheimer's disease}

Probiotics are bacteria that have beneficial effects on the health of the host person [8] while prebiotics are substances (mostly fiber) which serve as food for these bacteria. The data on the effects of probiotics (and prebiotics) in AD are not yet abundant. Some studies have investigated the effect of certain types of diet in humans. The results demonstrated that healthy dietary patterns characterized by high intake of probiotics and prebiotics, in association to other nutrients, delay neurocognitive decline and reduce the risk of $\mathrm{AD}$ [107]. In addition, it was shown that probiotic diet supplementation not only has an effect on normal brain activity [108] but also induces significant cognitive improvements in AD patients [109]. These effects may be due to the restoration of gut microbiota, but also to the contrasting action to other AD-related pathological events, such as oxidative stress and insulin resistance [109, 110]. More recently, it has been demonstrated that transgenic AD mice treated with probiotics, as compared to untreated $\mathrm{AD}$ mice, have better cognitive performance and reduced number of $\mathrm{A} \beta$ plaques in the hippocampus [111]. Similar effects on cognitive function in $\mathrm{AD}$ transgenic mice have been reported after prebiotic administration [112]. Finally, as stated before, probiotic administration in rats reverses the physiological and psychological alterations induced by administration of the antibiotic ampicillin [87].

\section{Conclusions: antibiotics or probiotics as AD therapies?}

As described above, alteration of the gut microbiota can induce changes in brain activity, which raises the possibility of therapeutic manipulation of the microbiome in $\mathrm{AD}$ and other neurological disorders (Fig. 1). The possibility of a

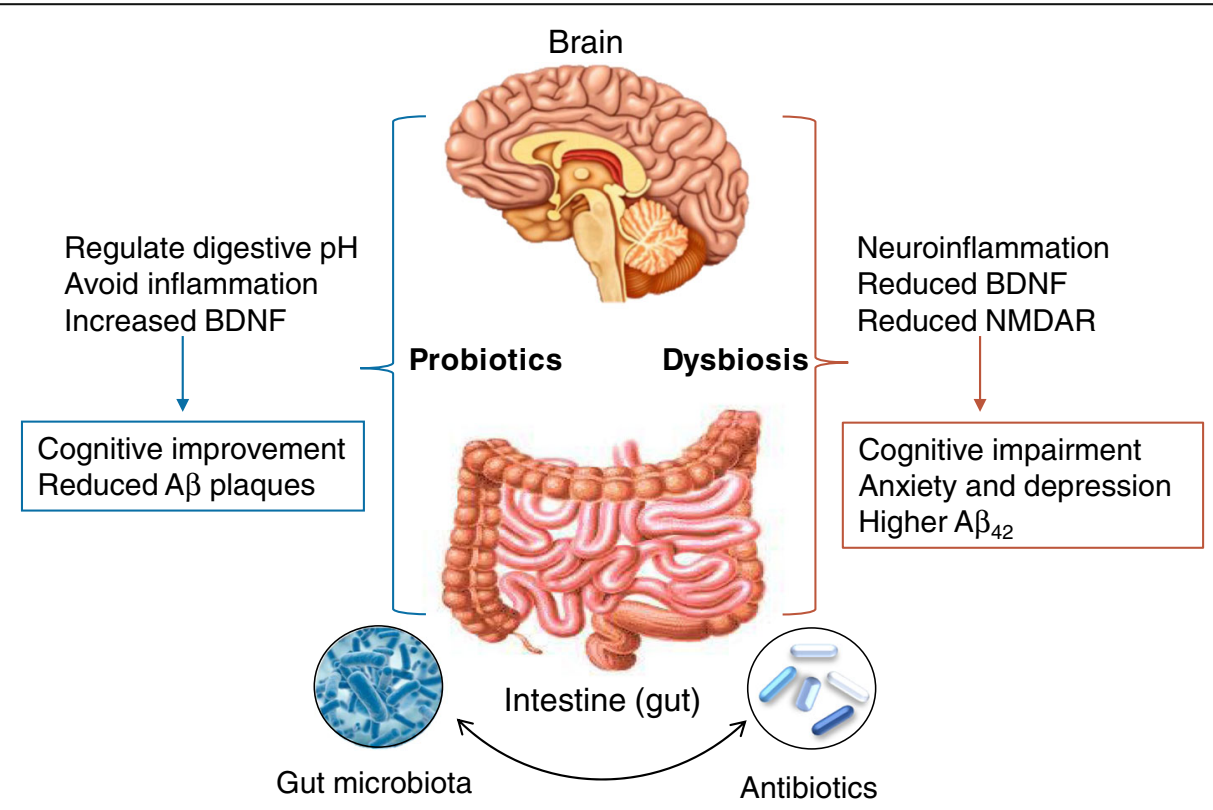

Fig. 1 Schematic representation of the role of microbiota-gut-brain axis in Alzheimer's disease. Good bacteria probiotics are capable to stabilize digestive $\mathrm{pH}$, reduce inflammation, and increase neuroprotective molecules, such as brain-derived neurotrophic factor (BDNF). These effects lead to improved cognition and reduced $A \beta$ plaque formation in $A D$ animal models. In contrast, impaired microbiota dysbiosis can induce neuroinflammation and reduce the expression of BDNF and NMDA receptor, leading to cognitive impairment, mood disorders, and higher levels of $A \beta_{42}$. Antibiotics, by affecting gut microbiota composition, interact with this circuit and produce different effects, depending on their microbiome target 
Table 1 Cited studies on the effects of antibiotics in AD rodent models and humans

\begin{tabular}{|c|c|c|c|c|}
\hline Antibiotic & Species & Target & Effects & References \\
\hline Streptozotocin & $\begin{array}{l}\text {-Mice } \\
\text {-Rats }\end{array}$ & $\begin{array}{l}\text {-Gram-positive bacteria } \\
\text {-Pancreatic islet cells }\end{array}$ & -Memory deficits & {$[90,93]$} \\
\hline Ampicillin & -Rats & -Gram-positive and Gram-negative bacteria & $\begin{array}{l}\text {-Increased serum corticosterone } \\
\text {-Increased anxiety } \\
\text {-Memory deficits }\end{array}$ & [87] \\
\hline Cefepime & -Humans & -Gram-positive and Gram-negative bacteria & -Reduced consciousness, myoclonus, confusion & [96] \\
\hline Amoxicillin & -Humans & -Gram-positive bacteria & -Improved cognition & [97] \\
\hline Rifampicin & $\begin{array}{l}\text {-Humans } \\
\text {-Rats } \\
\text {-Mice }\end{array}$ & -Bacterial DNA-dependent RNA synthesis & $\begin{array}{l}\text {-Anti-cholinesterase } \\
\text {-Anti-oxidative } \\
\text {-Anti-inflammatory } \\
\text {-Reduced } A \beta\end{array}$ & {$[98,102,103]$} \\
\hline Minocycline & $\begin{array}{l}\text {-Mice } \\
\text {-Rats }\end{array}$ & -Gram-positive and Gram-negative bacteria & $\begin{array}{l}\text {-Reduced inflammation and microglia activation } \\
\text {-Improved cognition } \\
\text {-Reduced } A \beta\end{array}$ & [99] \\
\hline Rapamycin & $\begin{array}{l}\text {-Mice } \\
\text {-Rats }\end{array}$ & $\begin{array}{l}\text {-Antifungal } \\
\text {-Immunosuppressant } \\
\text {-mTOR inhibitor }\end{array}$ & $\begin{array}{l}\text {-Improved cognition } \\
\text {-Reduced tau } \\
\text {-Reduced } A \beta \\
\text {-Reduced microglia activation }\end{array}$ & {$[100,105]$} \\
\hline D-Cycloserin & $\begin{array}{l}\text {-Humans } \\
\text {-Rats }\end{array}$ & $\begin{array}{l}\text {-Gram-positive and Gram-negative bacteria } \\
\text {-NMDA receptor partial agonist }\end{array}$ & -Improved cognition & {$[101,104]$} \\
\hline Doxycycline & $\begin{array}{l}\text {-Humans } \\
\text {-Mice }\end{array}$ & -Gram-positive and Gram-negative bacteria & $\begin{array}{l}\text {-Improved cognition } \\
\text {-Reduced inflammation }\end{array}$ & {$[102,103]$} \\
\hline
\end{tabular}

therapeutic, or preventive, intervention using antibiotics in $\mathrm{AD}$ is intriguing because of the cost benefits of such treatments, which could be relatively inexpensive and can be combined with specific dietary regimen with probiotics to act synergistically. This field of research is currently undergoing great development, but therapeutic applications are still far away. Whether a therapeutic manipulation of gut microbiota in AD could be achieved using antibiotics or probiotics is still not known. The action of antibiotics in $\mathrm{AD}$ could be wide and even opposite, depending on the type of antibiotic (Table 1) and on the specific role of the microbiome in $\mathrm{AD}$ pathogenesis.

As emerged from the studies mentioned, the use of antibiotics against gut microbiota specifically related to $\mathrm{AD}$ may be useful. The elimination of chronic infections caused by $H$. pylori or HSV1 virus can bring benefits to disease prevention, but also positive effects on cognitive functions. Nonetheless, clinical trials with antibiotics on patients already suffering from AD have led to conflicting results. Among the main problems, we must consider the multifactorial nature of the disease, which can be associated to an inflammatory state, but not exclusively. The presence of $H$. pylori infection, for example, may influence the outcome of a clinical trial, as its elimination may lead to cognitive improvements in affected patients, but it may prove ineffective in unaffected patients. Furthermore, there is always a real risk of causing dysbiosis in an attempt to reduce a state of neuroinflammation. Many antibiotics have a broad and not selective action on certain pathogens. In addition, other factors can affect the composition of the gut microbiota.
Among these, diet [113, 114], alcohol consumption [115], smoking [116], and changes in circadian rhythm [117] have been shown to affect the microbiota composition. The negative effects of antibiotics can be contrasted by the concomitant treatment with probiotics. Nevertheless, the development of antibiotics with selective antimicrobial action is desirable. A crucial factor is therefore the identification of the gut microbiota associated with the disease. At present, there are no definitive data on which types of gut microbiota are altered in AD. Thus, the future of antibiotics as therapeutics in $\mathrm{AD}$ depends on the research progresses in the role of gut microbiota.

Preclinical studies can certainly help to answer these questions. The manipulation of germ-free animals with various bacterial strains present in gut microbiota could provide specific indications on the possible therapeutic targets related to $\mathrm{AD}$. At that point, one can think of inducing gut microbiota modifications with the use of pre-, pro-, or antibiotics to obtain beneficial effects.

\footnotetext{
Abbreviations

AD: Alzheimer's disease; ApoE: Apolipoprotein E; Aß: Amyloid beta; BDNF: Brain-derived neurotrophic factor; GRIN2B: Glutamate ionotropic receptor NMDA type subunit 2B; HPA: Hypothalamic-pituitary-adrenal; IL: Interleukin; MCl: Mild cognitive impairment; MGBA: Microbiota-gut-brain axis; mTOR: Mammalian target of rapamycin; NMDA: N-Methyl-D-aspartate; NPY: Neuropeptide Y; NR2B: N-Methyl-D-aspartate receptor subtype 2B; SCFAs: Short-chain fatty acids; TDP-43: TAR DNA-binding protein 43; TGFbeta: Transforming growth factor beta; TNF-alpha: Tumor necrosis factor alpha; Treg: Regulatory $T$
}

Acknowledgements

None. 


\section{Funding}

This work is supported by IPE 2 (LF UK Grant No. 699012).

\section{Availability of data and materials}

Not applicable.

\section{Authors' contributions}

FA drafted the manuscript. $\mathrm{KC}, \mathrm{JA}$, and $\mathrm{JH}$ performed the critical editing and participated in the constructive outline, discussions, and editing. All authors read and approved the final manuscript.

\section{Ethics approval and consent to participate}

Not applicable.

\section{Consent for publication}

All authors consent for publication.

\section{Competing interests}

The authors declare that they have no competing interests.

\section{Publisher's Note}

Springer Nature remains neutral with regard to jurisdictional claims in published maps and institutional affiliations.

\section{Received: 6 February 2019 Accepted: 30 April 2019}

\section{Published online: 22 May 2019}

\section{References}

1. Viña J, Sanz-Ros J. Alzheimer's disease: only prevention makes sense. Eur J Clin Invest. 2018;48(10):e13005.

2. Jagust W. Imaging the evolution and pathophysiology of Alzheimer disease Nat Rev Neurosci. 2018;19:687-700 Available from: https://doi.org/10.1038/ s41583-018-0067-3

3. Xin SH, Tan L, Cao X, Yu JT, Tan L. Clearance of amyloid beta and tau in Alzheimer's disease: from mechanisms to therapy. Neurotox. Res. 2018;34(3): 733-48

4. Jiang C, Li G, Huang P, Liu Z, Zhao B. The gut microbiota and Alzheimer's disease. J Alzheimer's Dis. 2017;58:1-15 Available from: https://doi.org/10. 3233/jad-161141

5. Gareau MG. Microbiota-gut-brain axis and cognitive function. Adv Exp Med Biol. 2014:357-71 Available from: https://doi.org/10.1007/978-1-4939-0897-4_16.

6. Quigley EMM. Microbiota-brain-gut axis and neurodegenerative diseases Curr Neurol Neurosci Rep. 2017;17 Available from: https://doi.org/10.1007/ s11910-017-0802-6.

7. Calsolaro V, Edison P. Neuroinflammation in Alzheimer's disease: current evidence and future directions. Alzheimer's Dement. 2016:12:719-32 Available from: https://doi.org/10.1016/j.jalz.2016.02.010.

8. Mukherjee S, Joardar N, Sengupta S, Sinha Babu SP. Gut microbes as future therapeutics in treating inflammatory and infectious diseases: lessons from recent findings. J Nutr Biochem. 2018:61:111-28 Available from: https://doi. org/10.1016/j.jnutbio.2018.07.010.

9. Daliri EB-M, Tango CN, Lee BH, Oh D-H. Human microbiome restoration and safety. Int J Med Microbiol. 2018;308:487-97 Available from: https://doi.org/ 10.1016/j.jimm.2018.05.002

10. Collins SM, Surette M, Bercik P. The interplay between the intestinal microbiota and the brain. Nat Rev Microbiol. 2012;10:735-42 Available from: https://doi.org/10.1038/nrmicro2876.

11. Wekerle $\mathrm{H}$. The gut-brain connection: triggering of brain autoimmune disease by commensal gut bacteria. Rheumatology. 2016;55:ii68-75 Available from: https://doi.org/10.1093/rheumatology/kew353.

12. Briguglio M, Dell'Osso B, Panzica G, Malgaroli A, Banfi G, Zanaboni Dina C, et al. Dietary neurotransmitters: a narrative review on current knowledge. Nutrients. 2018;10:591 Available from: https://doi.org/10.3390/nu10050591.

13. Dinan TG, Cryan JF. The microbiome-gut-brain axis in health and disease Gastroenterol Clin North Am. 2017;46:77-89 Available from: https://doi.org/ 10.1016/j.gtc.2016.09.007

14. Bonaz B, Bazin T, Pellissier S. The vagus nerve at the interface of the microbiota-gut-brain axis. Front Neurosci. 2018;12:49.

15. Wang HX, Wang YP. Gut microbiota-brain axis. Chin Med J (Engl). 2016.
16. Carabotti M, Scirocco A, Maselli MA, Severi C. The gut-brain axis: Interactions between enteric microbiota, central and enteric nervous systems. Ann Gastroenterol. 2015;28(2):203-9.

17. Logsdon AF, Erickson MA, Rhea EM, Salameh TS, Banks WA. Gut reactions: how the blood-brain barrier connects the microbiome and the brain. Exp Biol Med. 2017;243:159-65 Available from: https://doi.org/10.1177/ 1535370217743766

18. Zac-Varghese S, Tan T, Bloom SR. Hormonal interactions between gut and brain. Discov Med. 2010:10(55):543-52.

19. Borre YE, Moloney RD, Clarke G, Dinan TG, Cryan JF. The impact of microbiota on brain and behavior: mechanisms \& therapeutic potential. Adv Exp Med Biol. 2014;817:373-403.

20. Links between gut microbes and depression strengthened. Nature. 2019; 566(7742):7

21. Galland L. The gut microbiome and the brain. J Med Food. 2014:17:1261-72 Available from: https://doi.org/10.1089/jmf.2014.7000.

22. Alam R, Abdolmaleky HM, Zhou J-R. Microbiome, inflammation, epigenetic alterations, and mental diseases. Am J Med Genet Part B Neuropsychiatr Genet. 2017:174:651-60 Available from: https://doi.org/10.1002/ajmg.b.32567.

23. Johnson KV-A, Foster KR. Why does the microbiome affect behaviour? Nat Rev Microbiol. 2018:16:647-55 Available from: https://doi.org/10.1038/ s41579-018-0014-3.

24. Gareau MG, Wine E, Rodrigues DM, Cho JH, Whary MT, Philpott DJ, et al. Bacterial infection causes stress-induced memory dysfunction in mice. Gut. 2010:60:307-17 Available from: https://doi.org/10.1136/gut.2009.202515.

25. Cox LM, Weiner HL. Microbiota signaling pathways that influence neurologic disease. Neurotherapeutics. 2018;15:135-45 Available from: https://doi.org/10.1007/s13311-017-0598-8.

26. Lach G, Schellekens H, Dinan TG, Cryan JF. Anxiety, depression, and the microbiome: a role for gut peptides. Neurotherapeutics. 2017:15:36-59 Available from: https://doi.org/10.1007/s13311-017-0585-0.

27. Braakman $\mathrm{HMH}$, van Ingen J. Can epilepsy be treated by antibiotics? J Neurol. 2018;265:1934-6 Available from: https://doi.org/10.1007/s00415-018-8943-3.

28. Barichella M, Severgnini M, Cilia R, Cassani E, Bolliri C, Caronni S, et al. Unraveling gut microbiota in Parkinson's disease and atypical parkinsonism. Mov Disord. 2018:34:396-405 Available from: https://doi.org/10.1002/mds.27581.

29. Kong G, Cao K-AL, Judd LM, Li S, Renoir T, Hannan AJ. Microbiome profiling reveals gut dysbiosis in a transgenic mouse model of Huntington's disease. Neurobiol Dis. 2018; Available from: https://doi.org/10.1016/j.nbd.2018.09.001.

30. Kirby T, Ochoa-Repáraz J. The gut microbiome in multiple sclerosis: a potential therapeutic avenue. Med Sci. 2018;6:69 Available from: https://doi. org/10.3390/medsci6030069

31. DiSabato DJ, Quan N, Godbout JP. Neuroinflammation: the devil is in the details. J Neurochem. 2016;139:136-53 Available from: https://doi.org/10. 1111/jnc.13607.

32. Minter MR, Taylor JM, Crack PJ. The contribution of neuroinflammation to amyloid toxicity in Alzheimer's disease. J Neurochem. 2015:136:457-74 Available from: https://doi.org/10.1111/jnc.13411.

33. Bagyinszky E, Van GV, Shim K, Suk K, An SSA, Kim S. Role of inflammatory molecules in the Alzheimer's disease progression and diagnosis. J Neurol Sci. 2017;376:242-54 Available from: https://doi.org/10.1016/j.jns.2017.03.031.

34. Wang M-M, Miao D, Cao X-P, Tan L, Tan L. Innate immune activation in Alzheimer's disease. Ann Transl Med. 2018;6:177 Available from: https://doi. org/10.21037/atm.2018.04.20

35. Selkoe DJ, Hardy J. The amyloid hypothesis of Alzheimer's disease at 25 years. EMBO Mol Med. 2016.

36. Jones L, Holmans PA, Hamshere ML, Harold D, Moskvina V, Ivanov D, et al. Genetic evidence implicates the immune system and cholesterol metabolism in the aetiology of Alzheimer's disease. PLoS One. 2010; 5(11):e13950.

37. Fan Z, Brooks DJ, Okello A, Edison P. An early and late peak in microglia activation in Alzheimer's disease trajectory. Brain. 2017:140(3):792-803.

38. Lambert JC, Heath S, Even G, Campion D, Sleegers K, Hiltunen M, et al. Genome-wide association study identifies variants at CLU and CR1 associated with Alzheimer's disease. Nat Genet. 2009;41(10):1094-9.

39. Bertram L, Lange C, Mullin K, Parkinson M, Hsiao M, Hogan MF, et al. Genome-wide association analysis reveals putative Alzheimer's disease susceptibility loci in addition to APOE. Am J Hum Genet. 2008:83(5):623-32.

40. Wang Y, Cella M, Mallinson K, Ulrich JD, Young KL, Robinette ML, et al. TREM2 lipid sensing sustains the microglial response in an Alzheimer's disease model. Cell. 2015;160(6):1061-71. 
41. Crehan $\mathrm{H}$, Hardy J, Pocock J. Blockage of CR1 prevents activation of rodent microglia. Neurobiol Dis. 2013;54:139-49.

42. Griciuc A, Serrano-Pozo A, Parrado AR, Lesinski AN, Asselin CN, Mullin K, et al. Alzheimer's disease risk gene cd33 inhibits microglial uptake of amyloid beta. Neuron. 2013;78(4):631-43.

43. Clark IA, Vissel B. Amyloid B: one of three danger-associated molecules that are secondary inducers of the proinflammatory cytokines that mediate Alzheimer's disease. Br J Pharmacol. 2015;172:3714-27 Available from: https://doi.org/10.1111/bph.13181.

44. Soscia SJ, Kirby JE, Washicosky KJ, Tucker SM, Ingelsson M, Hyman B, et al. The Alzheimer's disease-associated amyloid $\beta$-protein is an antimicrobial peptide. PLoS One. 2010;5:e9505 Available from: https://doi.org/10.1371/ journal.pone.0009505.

45. Games D, Adams D, Alessandrini R, Barbour R, Borthelette P, Blackwell C, et al. Alzheimer-type neuropathology in transgenic mice overexpressing V717F $\beta$-amyloid precursor protein. Nature. 1995;373(6514):523-7.

46. Cai Z, Hussain MD, Yan LJ. Microglia, neuroinflammation, and beta-amyloid protein in Alzheimer's disease. Int J Neurosci. 2014;124(5):307-21.

47. Dong Y, Li X, Cheng JHL. Drug development for Alzheimer's disease: microglia induced neuroinflammation as a target? Int J Mol Sci. 2019;20.

48. Pretorius E, Bester J, Kell DB. A bacterial component to Alzheimer's-type dementia seen via a systems biology approach that links iron dysregulation and inflammagen shedding to disease. J Alzheimers Dis. 2016;53:1237-56 Available from: https://doi.org/10.3233/jad-160318.

49. Hu X, Wang T, Jin F. Alzheimer's disease and gut microbiota. Sci China Life Sci [Internet]. Springer Nature. 2016;59:1006-23 Available from: https://doi. org/10.1007/s11427-016-5083-9.

50. Ashraf GM, Tarasov W, Makhmutova A, Chubarev VN, Avila-Rodriguez M, Bachurin SO, et al. The possibility of an infectious etiology of Alzheimer disease. Mol Neurobiol. 2018; Available from: https://doi.org/10.1007/s12035-018-1388-y.

51. Moir RD, Lathe R, Tanzi RE. The antimicrobial protection hypothesis of Alzheimer's disease. Alzheimers Dement. 2018;14:1602-14 Available from: https://doi.org/10.1016/j.jalz.2018.06.3040.

52. Michaud M, Balardy L, Moulis G, Gaudin C, Peyrot C, Vellas B, et al. Proinflammatory cytokines, aging, and age-related diseases. J Am Med Dir Assoc. 2013;14:877-82 Available from: https://doi.org/10.1016/j.jamda.2013.05.009.

53. Harach T, Marungruang N, Duthilleul N, Cheatham V, Mc Coy KD, Frisoni $\mathrm{G}$, et al. Reduction of Abeta amyloid pathology in APPPS1 transgenic mice in the absence of gut microbiota. Sci Rep. 2017;7 Available from: https://doi.org/10.1038/srep41802.

54. Roubaud-Baudron C, Quadrio I, Krolak-Salmon P, Mégraud F, Salles N. Impact of chronic Helicobacter pylori infection on Alzheimer's disease: preliminary results. Neurobiol Aging. 2011.

55. Bu XL, Yao XQ, Jiao SS, Zeng F, Liu YH, Xiang Y, et al. A study on the association between infectious burden and Alzheimer's disease. Eur J Neurol. 2015;22(12):1519-25.

56. Wang XL, Zeng J, Yang Y, Xiong Y, Zhang ZH, Qiu M, et al. Helicobacter pylori filtrate induces Alzheimer-like tau hyperphosphorylation by activating glycogen synthase kinase-3ß. J Alzheimers Dis. 2015;43:153-65.

57. Pisa Di AR, Fernández-Fernández AM, Rábano A, Carrasco L. Polymicrobial infections in brain tissue from Alzheimer's disease patients. Sci Rep. 2017;7(1):5559.

58. Zhao $Y$, Jaber VLW. Secretory products of the human GI tract microbiome and their potential impact on Alzheimer's disease (AD): detection of lipopolysaccharide (LPS) in AD hippocampus. Front Cell Infect Microbiol. 2017;7:318.

59. Cattaneo A, Cattane N, Galluzzi S, Provasi S, Lopizzo N, Festari C, et al. Association of brain amyloidosis with pro-inflammatory gut bacterial taxa and peripheral inflammation markers in cognitively impaired elderly. Neurobiol Aging. 2017:49:60-8.

60. Itzhaki RF. Herpes simplex virus type 1 and Alzheimer's disease: possible mechanisms and signposts. FASEB J. 2017;31(8):3216-26.

61. Barnes LL, Capuano AW, Aiello AE, Turner AD, Yolken RH, Torrey EF, et al. Cytomegalovirus infection and risk of Alzheimer disease in older black and white individuals. J Infect Dis. 2015;211(2):230-7.

62. Bernstein HG, Keilhoff G, Dobrowolny HSJ. Binding varicella zoster virus: an underestimated facet of insulin-degrading enzyme's implication for Alzheimer's disease pathology? Eur Arch Psychiatry Clin Neurosci. 2019.

63. Lin WR, Casas I, Wilcock GK, Itzhaki RF. Neurotropic viruses and Alzheimer's disease: a search for varicella zoster virus DNA by the polymerase chain reaction. J Neurol Neurosurg Psychiatry. 2008.
64. $L H, O J, W B, J A, E S, H G$, et al. Interaction between Cytomegalovirus and herpes simplex virus type 1 associated with the risk of Alzheimer's disease development. J Alzheimer's Dis. 2018.

65. Maqsood R, Stone TW. The gut-brain axis, BDNF, NMDA and CNS disorders. Neurochem Res. 2016;41:2819-35 Available from: https://doi.org/10.1007/ s11064-016-2039-1.

66. Marques C, Meireles M, Faria A, Calhau C. High-fat diet-induced dysbiosis as a cause of neuroinflammation. Biol Psychiatry. 2016;80:e3-4 Available from: https://doi.org/10.1016/j.biopsych.2015.10.027.

67. Li H, Sun J, Du J, Wang F, Fang R, Yu C, et al. Clostridium butyricum exerts a neuroprotective effect in a mouse model of traumatic brain injury via the gut-brain axis. Neurogastroenterol Motil. 2017;30:e13260 Available from: https://doi.org/10.1111/nmo.13260.

68. Morrison DJ, Preston T. Formation of short chain fatty acids by the gut microbiota and their impact on human metabolism. Gut Microbes. 2016;7: 189-200 Available from: https://doi.org/10.1080/19490976.2015.1134082.

69. Caracciolo B, Xu W, Collins S, Fratiglioni L. Cognitive decline, dietary factors and gut-brain interactions. Mech Ageing Dev. 2014;136(137):59-69 Available from: https://doi.org/10.1016/j.mad.2013.11.011.

70. Claesson MJ, Jeffery IB, Conde S, Power SE, O'Connor EM, Cusack S, et al. Gut microbiota composition correlates with diet and health in the elderly. Nature. 2012;488:178-84 Available from: https://doi.org/10.1038/nature11319.

71. Franceschi $\mathrm{C}$, Bonafè $\mathrm{M}$, Valensin $\mathrm{S}$, Olivieri $\mathrm{F}$, De Luca $\mathrm{M}$, Ottaviani $\mathrm{E}$, et al. Inflamm-aging: an evolutionary perspective on immunosenescence. Ann N Y Acad Sci. 2006;908:244-54 Available from: https://doi.org/10.1111/j.17496632.2000.tb06651.x

72. Minter MR, Zhang C, Leone V, Ringus DL, Zhang X, Oyler-Castrillo P, et al. Antibiotic-induced perturbations in gut microbial diversity influences neuroinflammation and amyloidosis in a murine model of Alzheimer's disease. Sci Rep. 2016;6 Available from: https://doi.org/10.1038/srep30028.

73. Erny $D$, Hrabě de Angelis AL, Jaitin D, Wieghofer $P$, Staszewski $O$, David $E$, et al. Host microbiota constantly control maturation and function of microglia in the CNS. Nat Neurosci. 2015;18:965-77 Available from: https://doi.org/10. $1038 / \mathrm{nn} .4030$

74. Ege MJ. The hygiene hypothesis in the age of the microbiome. Ann Am Thorac Soc. 2017;14:S348-53 Available from: https://doi.org/10.1513/ annalsats.201702-139aw.

75. Browne TC, McQuillan K, McManus RM, O'Reilly J-A, Mills KHG, Lynch MA. IFN- $\gamma$ production by amyloid $\beta$-specific Th1 cells promotes microglial activation and increases plaque burden in a mouse model of Alzheimer's disease. J Immunol. 2013;190:2241-51 Available from: https://doi.org/10. 4049/jimmunol.1200947.

76. Pellicanò M, Larbi A, Goldeck D, Colonna-Romano G, Buffa S, Bulati M, et al. Immune profiling of Alzheimer patients. J Neuroimmunol. 2012;242:52-9 Available from: https://doi.org/10.1016/j.jneuroim.2011.11.005.

77. Saresella M, Calabrese E, Marventano I, Piancone F, Gatti A, Calvo MG, et al. PD1 negative and PD1 positive CD4+ T regulatory cells in mild cognitive impairment and Alzheimer's disease. J Alzheimer's Dis. 2010;21:927-38 Available from: https://doi.org/10.3233/jad-2010-091696.

78. Dansokho C, Ait Ahmed D, Aid S, Toly-Ndour C, Chaigneau T, Calle V, et al. Regulatory T cells delay disease progression in Alzheimer-like pathology. Brain. 2016;139:1237-51 Available from: https://doi.org/10.1093/brain/awv408.

79. Larbi A, Pawelec G, Witkowski JM, Schipper HM, Derhovanessian E, Goldeck $D$, et al. Dramatic shifts in circulating cd4 but not cd8 t cell subsets in mild alzheimer's disease. J Alzheimer's Dis. 2009;17:91-103 Available from: https:// doi.org/10.3233/jad-2009-1015.

80. Itzhaki RF, Wozniak MA. Herpes simplex virus type 1 in Alzheimer's disease: the enemy within. J Alzheimer's Dis. 2008;13:393-405 Available from: https://doi.org/10.3233/jad-2008-13405.

81. Laitinen MH, Ngandu T, Rovio S, Helkala E-L, Uusitalo U, Viitanen M, et al. Fat intake at midlife and risk of dementia and Alzheimer's disease: a population-based study. Dement Geriatr Cogn Disord. 2006;22:99-107 Available from: https://doi.org/10.1159/000093478.

82. Ianiro G, Tilg H, Gasbarrini A. Antibiotics as deep modulators of gut microbiota: between good and evil. Gut. 2016;65:1906-15 Available from: https://doi.org/10.1136/gutjnl-2016-312297.

83. Neuman $\mathrm{H}$, Forsythe $\mathrm{P}$, Uzan A, Avni O, Koren O. Antibiotics in early life: dysbiosis and the damage done. FEMS Microbiol Rev. 2018; Available from: https://doi.org/10.1093/femsre/fuy018.

84. Fröhlich EE, Farzi A, Mayerhofer R, Reichmann F, Jačan A, Wagner B, et al. Cognitive impairment by antibiotic-induced gut dysbiosis: analysis of gut 
microbiota-brain communication. Brain Behav Immun. 2016;56:140-55 Available from: https://doi.org/10.1016/j.bbi.2016.02.020.

85. Neufeld NH, Mohamed NS, Grujich N, Shulman K. Acute neuropsychiatric symptoms associated with antibiotic treatment of Helicobacter pylori infections. J Psychiatr Pract. 2017;23:25-35 Available from: https://doi.org/10. 1097/pra.0000000000000205.

86. Zarrinpar A, Chaix A, Xu ZZ, Chang MW, Marotz CA, Saghatelian A, et al. Antibiotic-induced microbiome depletion alters metabolic homeostasis by affecting gut signaling and colonic metabolism. Nat Commun. 2018;9 Available from: https://doi.org/10.1038/s41467-018-05336-9.

87. Wang T, Hu X, Liang S, Li W, Wu X, Wang L, et al. Lactobacillus fermentum NS9 restores the antibiotic induced physiological and psychological abnormalities in rats. Benef Microbes. 2015;6:707-17 Available from: https:// doi.org/10.3920/bm2014.0177.

88. Neufeld KM, Kang N, Bienenstock J, Foster JA. Reduced anxiety-like behavior and central neurochemical change in germ-free mice. Neurogastroenterol Motil. 2010;23:255-e119 Available from: https://doi.org/10.1111/j.1365-2982. 2010.01620.x.

89. Bercik P, Denou E, Collins J, Jackson W, Lu J, Jury J, et al. The intestinal microbiota affect central levels of brain-derived neurotropic factor and behavior in mice. Gastroenterology. 2011;141:599-609.e3 Available from: https://doi.org/10.1053/j.gastro.2011.04.052.

90. Ravelli KG, Rosário B dos A, Camarini R, Hernandes MS, Britto LR Intracerebroventricular streptozotocin as a model of Alzheimer's disease: neurochemical and behavioral characterization in mice. Neurotox Res. 2016; 31:327-33 Available from: https://doi.org/10.1007/s12640-016-9684-7.

91. Furman BL. Streptozotocin-induced diabetic models in mice and rats. Curr Protoc Pharmacol. 2015:5.47.1, 5.47.20 Available from: https://doi.org/10. 1002/0471141755.ph0547s70.

92. Walker J, Harrison F. Shared neuropathological characteristics of obesity, type 2 diabetes and Alzheimer's disease: impacts on cognitive decline. Nutrients. 2015;7:7332-57 Available from: https://doi.org/10.3390/nu7095341.

93. Davari S, Talaei SA, Alaei H, Salami M. Probiotics treatment improves diabetes-induced impairment of synaptic activity and cognitive function: behavioral and electrophysiological proofs for microbiome-gut-brain axis. Neuroscience. 2013;240:287-96 Available from: https://doi.org/10.1016/j. neuroscience.2013.02.055.

94. Desbonnet L, Clarke G, Shanahan F, Dinan TG, Cryan JF. Microbiota is essential for social development in the mouse. Mol Psychiatry. 2013;19:1468 Available from: https://doi.org/10.1038/mp.2013.65.

95. Desbonnet L, Clarke G, Traplin A, O'Sullivan O, Crispie F, Moloney RD, et al. Gut microbiota depletion from early adolescence in mice: implications for brain and behaviour. Brain Behav Immun. 2015;48:165-73 Available from: https://doi.org/10.1016/j.bbi.2015.04.004.

96. Payne LE, Gagnon DJ, Riker RR, Seder DB, Glisic EK, Morris JG, et al. Cefepime-induced neurotoxicity: a systematic review. Crit Care. 2017;21 Available from: https://doi.org/10.1186/s13054-017-1856-1.

97. Kountouras J, Boziki M, Gavalas E, Zavos C, Grigoriadis N, Deretzi G, et al. Eradication of Helicobacter pylori may be beneficial in the management of Alzheimer's disease. J Neurol. 2009;256:758-67 Available from: https://doi. org/10.1007/s00415-009-5011-z

98. Yulug B, Hanoglu L, Ozansoy M, Isık D, Kilic U, Kilic E, et al. Therapeutic role of rifampicin in Alzheimer's disease. Psychiatry Clin Neurosci. 2018;72:152-9 Available from: https://doi.org/10.1111/pcn.12637.

99. Budni J, L. Garcez M, de Medeiros J, Cassaro E, Bellettini-Santos T, Mina F, et al. The anti-inflammatory role of minocycline in Alzheimer's disease. Curr Alzheimer Res ; 2016;13:1319-1329. Available from: https://doi.org/10.2174/ 1567205013666160819124206

100. Wang C, Yu J-T, Miao D, Wu Z-C, Tan M-S, Tan L. Targeting the mTOR signaling network for Alzheimer's disease therapy. Mol Neurobiol. 2013;49: 120-35 Available from: https://doi.org/10.1007/s12035-013-8505-8.

101. Portero-Tresserra M, Martí-Nicolovius M, Tarrés-Gatius M, Candalija A, Guillazo-Blanch G, Vale-Martínez A. Intra-hippocampal d-cycloserine rescues decreased social memory, spatial learning reversal, and synaptophysin levels in aged rats. Psychopharmacology (Berl). 2018;235(5):1463-77.

102. Tsai GE, Falk WE, Gunther J, Coyle JT. Improved cognition in Alzheimer's disease with short-term D-cycloserine treatment. Am J Psychiatry. 1999;156(3):467-9.

103. Loeb MB, Molloy DW, Smieja M, Standish T, Goldsmith CH, Mahony J, et al. A randomized, controlled trial of doxycycline and rifampin for patients with Alzheimer's disease. J Am Geriatr Soc. 2004;52:381-7 Available from: https://doi.org/10.1111/j.1532-5415.2004.52109.x.
104. Molloy DW, Standish TI, Zhou Q, Guyatt G. A multicenter, blinded, randomized, factorial controlled trial of doxycycline and rifampin for treatment of Alzheimer's disease: the DARAD trial. Int J Geriatr Psychiatry. 2012;28:463-70 Available from: https://doi.org/10.1002/gps.3846.

105. Jones R, Laake K, Øksengård AR. D-cycloserine for Alzheimer's disease. Cochrane Database Syst Rev. 2002; Available from: https://doi.org/10.1002/ 14651858.cd003153.

106. Richardson A, Galvan V, Lin A-L, Oddo S. How longevity research can lead to therapies for Alzheimer's disease: the rapamycin story. Exp Gerontol. 2015;68:51-8 Available from: https://doi.org/10.1016/j.exger.2014.12.002.

107. Pistollato F, Iglesias RC, Ruiz R, Aparicio S, Crespo J, Lopez LD, et al. Nutritional patterns associated with the maintenance of neurocognitive functions and the risk of dementia and Alzheimer's disease: a focus on human studies. Pharmacol. Res. 2018.

108. Tillisch K, Labus J, Kilpatrick L, Jiang Z, Stains J, Ebrat B, et al. Consumption of fermented milk product with probiotic modulates brain activity. Gastroenterology. 2013.

109. Akbari E, Asemi Z, Kakhaki RD, Bahmani F, Kouchaki E, Tamtaji OR, et al. Effect of probiotic supplementation on cognitive function and metabolic status in Alzheimer's disease: a randomized, double-blind and controlled trial. Front Aging Neurosci. 2016.

110. Athari Nik Azm S, Djazayeri A, Safa M, Azami K, Ahmadvand B, Sabbaghziarani F, et al. Lactobacillus and bifidobacterium ameliorate memory and learning deficits and oxidative stress in $A \beta$ (1-42) injected Rats. Appl Physiol Nutr Metab. 2018.

111. Abraham D, Feher J, Scuderi GL, Szabo D, Dobolyi A, Cservenak M, et al. Exercise and probiotics attenuate the development of Alzheimer's disease in transgenic mice: role of microbiome. Exp Gerontol. 2019.

112. Chen D, Yang X, Yang J, Lai G, Yong T, Tang X, et al. Prebiotic effect of Fructooligosaccharides from Morinda officinalis on Alzheimer's disease in rodent models by targeting the microbiota-gut-brain axis. Front Aging Neurosci. 2017.

113. Gentile CL, Weir TL. The gut microbiota at the intersection of diet and human health. Science (80- ). 2018;362:776-80 Available from: https://doi. org/10.1126/science.aau5812.

114. Yang B-G, Hur KY, Lee M-S. Alterations in gut microbiota and immunity by dietary fat. Yonsei Med J. 2017;58:1083 Available from: https://doi.org/10. 3349/ymj.2017.58.6.1083.

115. Hillemacher T, Bachmann O, Kahl KG, Frieling H. Alcohol, microbiome, and their effect on psychiatric disorders. Prog Neuropsychopharmacol Biol Psychiatry. 2018, 85:105-15 Available from: https://doi.org/10.1016/j.pnpbp.2018.04.015.

116. Savin Z, Kivity S, Yonath H, Yehuda S. Smoking and the intestinal microbiome. Arch Microbiol. 2018;200:677-84 Available from: https://doi. org/10.1007/s00203-018-1506-2.

117. Kaczmarek JL, Thompson SV, Holscher HD. Complex interactions of circadian rhythms, eating behaviors, and the gastrointestinal microbiota and their potential impact on health. Nutr Rev. 2017;75:673-82 Available from: https://doi.org/10.1093/nutrit/nux036.

Ready to submit your research? Choose BMC and benefit from:

- fast, convenient online submission

- thorough peer review by experienced researchers in your field

- rapid publication on acceptance

- support for research data, including large and complex data types

- gold Open Access which fosters wider collaboration and increased citations

- maximum visibility for your research: over $100 \mathrm{M}$ website views per year

At BMC, research is always in progress.

Learn more biomedcentral.com/submissions 